\title{
The Evolution of Primitive Reflexes in Extremely Premature Infants
}

\author{
M. C. ALLEN AND A. J. CAPUTE \\ Department of Pediatrics and Eudowood Neonatal Division, The Johns Hopkins University School of Medicine \\ and The John F. Kennedy Institute for Handicapped Children, Baltimore, Maryland
}

\begin{abstract}
A longitudinal study describes the pattern of appearance of eight primitive reflexes in a population of 47 viable extremely premature infants, beginning as early as 25 wk postconceptional age (PCA). Infants were examined weekly, from 1 wk of age until discharge from the neonatal intensive care unit. Primitive reflexes were graded as to completeness and intensity of response. Three patterns emerged: 1) the upper and lower extremity grasp reflexes were present in all premature infants, from $25 \mathrm{wk}$ and beyond, 2) the Moro, asymmetric tonic neck reflex and Galant (lateral trunk incurvature reflex) were present in some premature infants as early as 25 wk PCA, and in the majority by 30 wk PCA, and 3) the lower extremity placing, positive support, and stepping were occasionally present prior to $30 \mathrm{wk}$ PCA, yet were not uniformly present and/or complete even at term. In each case, the primitive reflex became stronger, more complete, more consistently elicited and more prevalent with increasing postconceptional age. The pattern of primitive reflexes in the premature infant at term (40 wk PCA) is similar to that of fullterm newborns. Sequential assessment of the primitive reflexes may be a useful method of evaluating extremely premature infants prior to term. (Pediatr Res 20: 12841289, 1986)
\end{abstract}

\section{Abbreviations}

ATNR, asymmetric tonic neck reflex

PCA, postconceptional age (the sum of gestational age and chronologic age)

PVL, periventricular leukomalacia

The primitive reflexes were one of the earliest tools used to assess the central nervous system integrity of full-term newborns (1-9). They are brain-stem mediated, complex automatic movement patterns that are present at birth in full-term infants and, with central nervous system maturation, become more difficult to elicit later in the 1 st yr of life, when voluntary motor activity is emerging (10-14). Although Touwen (15) has argued that primitive reflexes are neither primitive nor reflexes, he acknowledges that they and their developmental course are useful components of the neurologic examination in infancy. Unusually strong or persistent primitive reflexes are present in children with cerebral palsy, and may be early markers of neurologic dysfunction $(4,16-21)$.

Capute and associates (10-14) have graded the primitive reflexes as to strength and completeness of response, and have described their evolution in a longitudinal study of full term

Correspondence received May 31, 1985; accepted July 22, 1986.

Marilee C. Allen, M.D., CMSC 210, The Johns Hopkins Hospital, 600 N. Wolfe Street, Baltimore, MD 21205 infants, from birth through infancy. In the only published longitudinal study in premature infants, the primitive reflexes were not graded and their frequency in the population was not reported (9). In addition, the population was limited to selected premature infants beyond $28 \mathrm{wk}$ gestation. The only descriptions of primitive reflexes less than $28 \mathrm{wk}$ gestation are in nonviable aborted fetuses prior to their death $(9,23-25)$. Observers using ultrasound have observed fetal movements, but have not yet described discrete primitive reflexes in utero (26).

With improved obstetric and neonatal care, the lower limit of viability is now as low as 23 to $24 \mathrm{wk}$ gestation. Not only has survival improved, but the majority of these infants has the potential for a life free of major handicap (27-29). It is therefore possible, and may be useful, to observe the pattern of appearance of the primitive reflexes in these viable extremely premature infants.

This longitudinal study describes the appearance and evolution of selected primitive reflexes in 47 viable extremely premature infants, documented by weekly examinations, from 1 wk of age until discharge from the neonatal intensive care unit. The upper extremity (palmar) and lower extremity (plantar) grasp reflexes, Moro, ATNR, Galant (lateral trunk incurvature), lower extremity placing, positive support, and stepping (automatic walking) were selected for analysis

\section{METHODS}

All premature infants with birth weights less than $1300 \mathrm{~g}$ born at The Johns Hopkins Hospital in 1983 were examined weekly, beginning at 1 wk of age, until the time of discharge. Of 69 infants meeting these criteria, $56(81 \%)$ survived the neonatal period. Birthweight ranged from 460 to $1280 \mathrm{~g}$ (mean $960 \mathrm{~g}$ ). Gestational age ranged from 24 to 33 wk (mean 27.9 wk). Thirtyeight $(68 \%)$ were at or below 28 wk gestation at the time of birth.

Gestational age was determined by mother's dates in the majority (>90\%) of infants, and was generally confirmed by obstetric examination, sonographic data, and the neonatologist's assessment. Although it was used in two infants in whom dates were confusing, the Dubowitz assessment of gestational age (30) has not been useful in these extremely premature infants. The Dubowitz differed from the gestational age (as determined by dates, examination, and sonographic dates) by more than $1 \mathrm{wk}$ in $60 \%$, and by more than 2 wk in $32 \%$.

Weekly examinations ( \pm 2 days) were performed in all infants by a neonatologist/developmental pediatrician. The examination was deferred if the infant was unstable (e.g. with sepsis, pneumothorax, or necrotizing enterocolitis), and was resumed when the infant was stable. Although $50(89 \%)$ infants were initially intubated, $24(43 \%)$ were not on a ventilator at the time of their first examination. Nine (16\%) infants with severe chronic lung disease and/or severe (grade IV) intraventricular hemorrhage required prolonged mechanical ventilation, for $12 \mathrm{wk}$ or more. Their outcome was uniformly poor: six died and three have 
cerebral palsy. This discrete group of premature infants with uniformly poor outcome were excluded from analysis, and will be reported separately.

All 47 premature infants had cranial ultrasound examinations during the first $2 \mathrm{wk}$ of life. The majority $(60 \%)$ had two or more examinations (generally at 4-7 days, then at 10-14 days, with subsequent follow-up if abnormal). Thirty-three $(70 \%)$ had no evidence of periventricular/intraventricular hemorrhage. Nine $(19 \%)$ had grade I periventricular hemorrhage, four $(9 \%)$ had grade II intraventricular hemorrhage, and one infant had blood in the ventricles with moderately dilated ventricles (grade III intraventricular hemorrhage). One infant had grade I periventricular hemorrhage with bilateral multiple periventricular cysts, suggestive of $\mathrm{PVL}$.

The appearance of eight primitive reflexes are described in 47 premature infants. Of these infants, $38 \%$ were male, $62 \%$ female, $30 \%$ white, and $70 \%$ black. Data were incomplete in two: one was a 28 -wk premature infant with hemophilia and was not examined until $6 \mathrm{wk}$ of age, one was transferred to a community hospital at 3 wk of age. A total of 397 examinations was performed, an average of 8.4 per infant. Data are reported on the basis of postconceptional age (PCA, the sum of chronologic age and gestational age), in 2-wk intervals.

The primitive reflexes were elicited in the following manner.

1) Upper extremity grasp reflex-pressure over the palm elicits finger flexion. Subsequent traction on the arm reinforces the grip and elicits flexion at the elbow (and shoulder).

2) Lower extremity grasp reflex-pressure at the base of the toes elicits plantar flexion of the toes.

3) Moro-the examiner lifts the infant's head and gently allows it to fall back into the examiner's hand. This elicits abduction and extension of the upper extremities, followed by adduction and flexion.

4) ATNR-when the infant's head is turned to one side, the limbs on the face side extend, and the limbs on the occiput side flex. If changes in posture are not noted, then the limbs are examined for changes in tone. Consistent changes (three of five trials) in tone or posture must be elicited in an upper and lower extremity to be scored as present, and the grade is based on the limb with the highest score.

5) Galant-stroking the back along the paravertebral area elicits lateral trunk incurvature (flexion) toward that side.

6) Lower extremity placing-while holding the infant in vertical suspension, the shin and dorsum of the foot is brought into contact with the edge of the bed or table. This elicits initial flexion of the hip and knee followed by extension (thereby "placing" his foot on the table).

7) Positive support-bouncing the child vertically on his feet six times elicits brief weight bearing.

8) Stepping-supporting the child in standing and leaning him forward elicits reciprocal flexion and extension of the lower extremities.

They were all graded as to completeness and intensity of expression (see Figure legends). The Moro, ATNR, Galant, and positive support were graded in the manner of, or modified from Capute et al. $(10,13)$. A grading system was developed for the upper and lower extremity grasp reflexes, lower extremity placing, and stepping.

\section{RESULTS}

Upper extremity (palmar) grasp reflex. Some degree of finger flexion in response to palmar stimulation was always present even in the most immature infants (Fig. 1). Flexion at the elbow (the traction component, grade 3 ) could be elicited as early as 29 to $30 \mathrm{wk}$ PCA, and was generally present by 37 to $38 \mathrm{wk}$ PCA. The upper extremity grasp reflex was strong enough to pick the infant up off the bed (grade 4 ) in $40 \%$ at term (39 to $40 \mathrm{wk}$ PCA).

Lower extremity (plantar) grasp reflex. The lower extremity grasp reflex was always present on the initial examination at 1 wk of age (Fig. 2). Although this reflex was initially weak in some infants, the strength of the toe flexion increased with postconceptional age.

Moro. The initial component of the Moro, with extension and/or abduction of the upper extremities (grade 1), was generally present by 25 to 26 wk PCA (Fig. 3). Subsequent adduction or flexion (grade 2) appeared at 27 to 28 wk PCA. The complete reflex (grade 3 ) appeared at 29 to $30 \mathrm{wk}$ PCA and was present in $75 \%$ at term.

$A T N R$. Four of five infants examined at 25 to $26 \mathrm{wk}$ PCA had some evidence of the ATNR in both upper and lower extremities (Fig. 4). By 31 to 32 wk PCA, $98 \%$ had some evidence of an ATNR, and beyond 33 wk PCA, all infants had an ATNR. The proportion of infants with tone changes only (grade 1) decreased from $40 \%$ at 25 to 26 wk PCA to $2 \%$ at 33 to 34 wk PCA. Changes in posture (grades 2 and 3) predominated by 29 to 30 wk PCA. The strong response (grade 3 ) became increasingly prevalent, occurring in almost half ( 44 to $48 \%$ ) by 35 to $40 \mathrm{wk}$ PCA

Galant. Trunk incurvature (grades 1, 2, and 3) was demonstrated in only one of five infants examined at 25 to 26 wk PCA, but rapidly became more frequent and stronger with increasing postconceptional age (Fig. 5). As with the ATNR, $98 \%$ of premature infants had a Galant by 31 to 32 wk PCA. The strongest response, trunk incurvature with hip elevation (grade 4), appeared at 29 to $30 \mathrm{wk}$ PCA, and was present in 38 to $44 \%$ of infants beyond $35 \mathrm{wk}$ PCA.

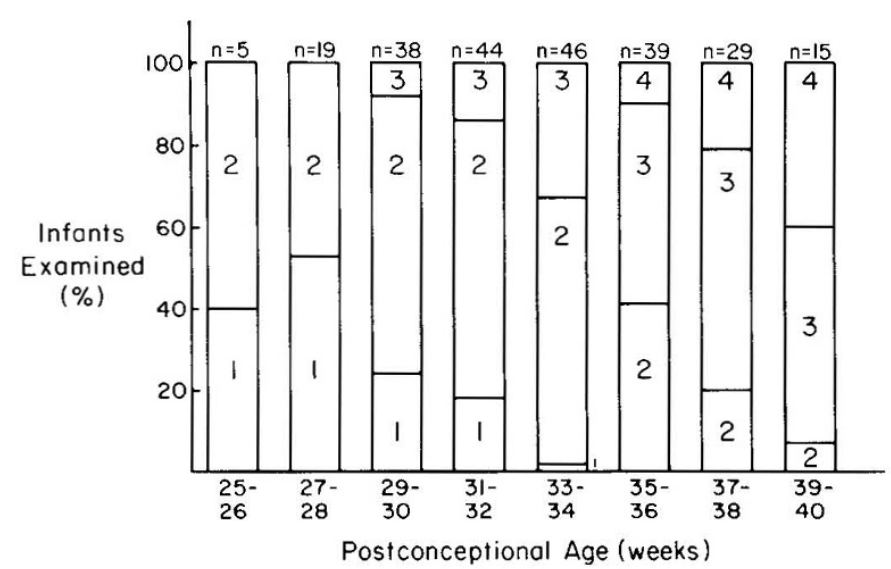

Fig. 1. Upper extremity grasp reflex in extremely premature infants prior to term. Grading: $0=$ absent, $1=$ weak finger flexion, $2=$ strong finger flexion, 3 = finger flexion with elbow flexion on traction, $4=$ strong enough flexion to lift the infant off the bed.

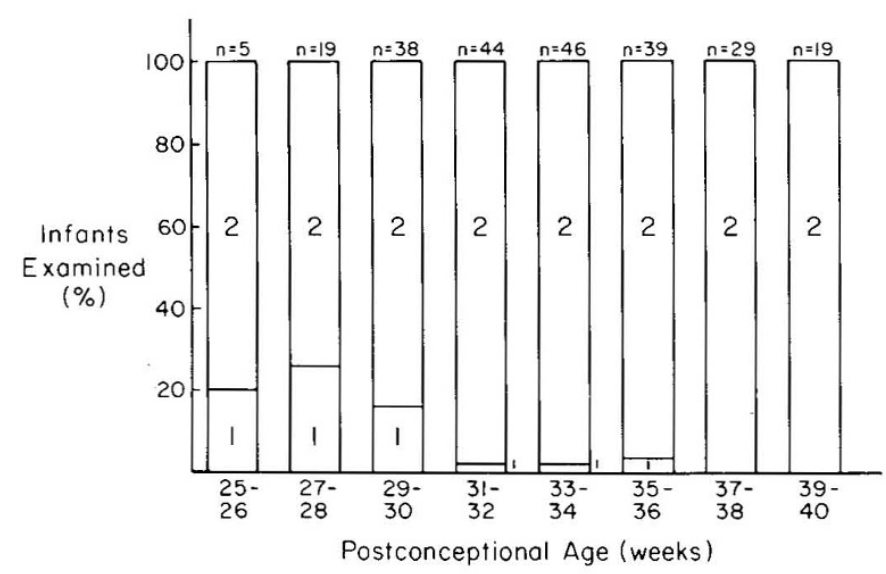

Fig. 2. Lower extremity grasp reflex in extremely premature infants prior to term. Grading: $0=$ absent, $1=$ weak toe flexion, $2=$ strong toe flexion. 


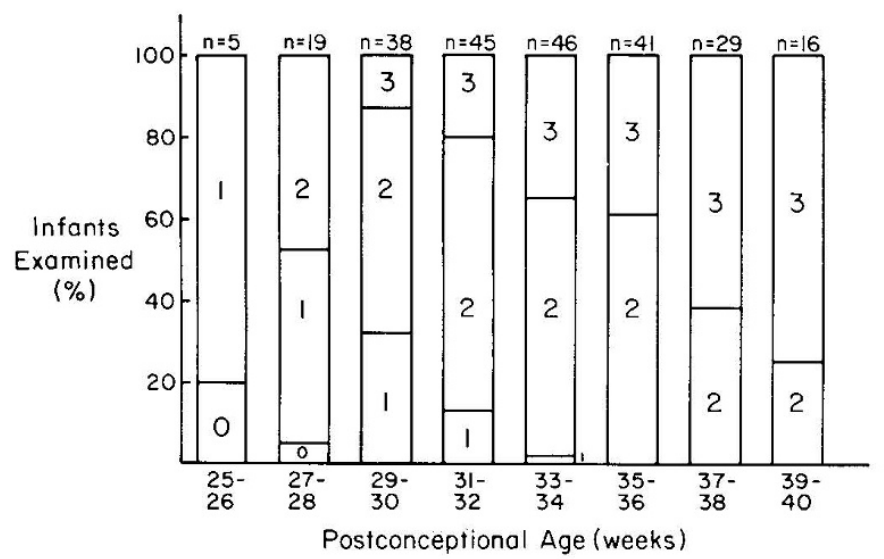

Fig. 3. Moro reflex in extremely premature infants prior to term. Grading: $0=$ absent, $1=$ some abduction or extension, no adduction or flexion, 2 = abduction and extension, followed by some adduction and/ or flexion, 3 = complete Moro (abduction and extension, followed by strong adduction and flexion), $4=$ complete Moro with arching of the back and/or opisthotonic posturing.

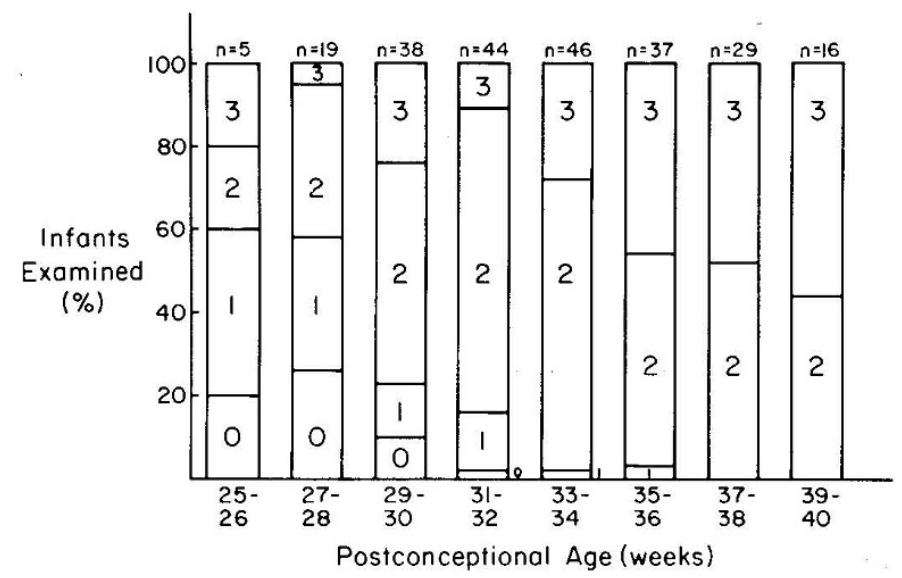

Fig. 4. ATNR in extremely premature infants prior to term. Grading: $0=$ absent, $1=$ tone changes only, $2=$ visible changes in posture, $3=$ full extension $\left(180^{\circ}\right)$ of limb on face side or full flexion $\left(<90^{\circ}\right)$ of limb on occiput side for $<30 \mathrm{~s}, 4=$ obligatory, full extension and/or flexion for $>30 \mathrm{~s}$

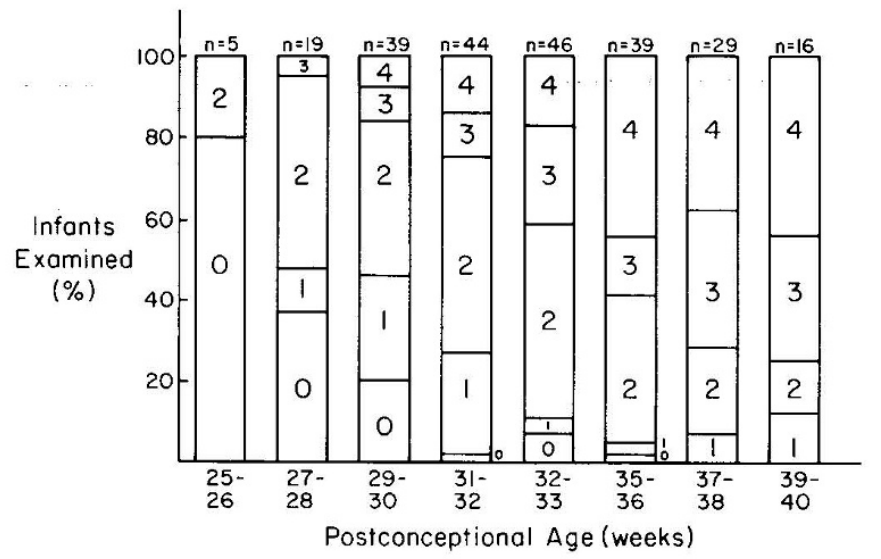

Fig. 5. Galant reflex in extremely premature infants prior to term. Grading: $0=$ absent, $1=$ mild, inconsistent trunk incurvature (felt more than seen), $2=$ definite, visible trunk incurvature, $3=$ exaggerated trunk incurvature, with hips swinging to $45^{\circ}$ angle or more with the spine, $4=$ definite or exaggerated trunk incurvature with hip elevation.
Lower extremity placing. Mild initial flexion (grade 1) occurred in $33 \%$ of premature infants at 27 to $28 \mathrm{wk}$ and in $67 \%$ by 29 to 30 wk PCA (Fig. 6). Stronger flexion with some subsequent extension (grade 2) began at 29 to $30 \mathrm{wk}$. Complete lower extremity placing, with brisk initial flexion followed by extension (grade 3 ) emerged at 31 to $32 \mathrm{wk}$, and was present in the majority by 35 to 36 wk. At term, $80 \%$ had the complete, brisk lower extremity placing reflex (grade 3 ).

Positive support. Although some infants demonstrated the positive support as early as $27 \mathrm{wk}$ PCA (Fig. 7), the response in the majority of infants less than 35 wk PCA was inconsistent (grade $0-1)$. The majority ( $86 \%$ ) of the premature infants at term demonstrated the newborn positive support, in that they could consistently bear weight on their lower extremities for 1 to $2 \mathrm{~s}$ (grade 1).

Stepping. Equivocal stepping (grade 1) could be elicited in one infant as early as 27 to 28 wk (Fig. 8). The complete stepping responses (grades 2 and 3) first appeared at 29 to 30 wk PCA, was present in $38 \%$ by 35 to 36 wk PCA, and was present in only half the infants $(56 \%)$ at term. Only $25 \%$ of premature infants at term had the exaggerated stepping (grade 3 ).

Effect of periventricular intraventricular hemorrhage. The evolution of each primitive reflex was analyzed with respect to the

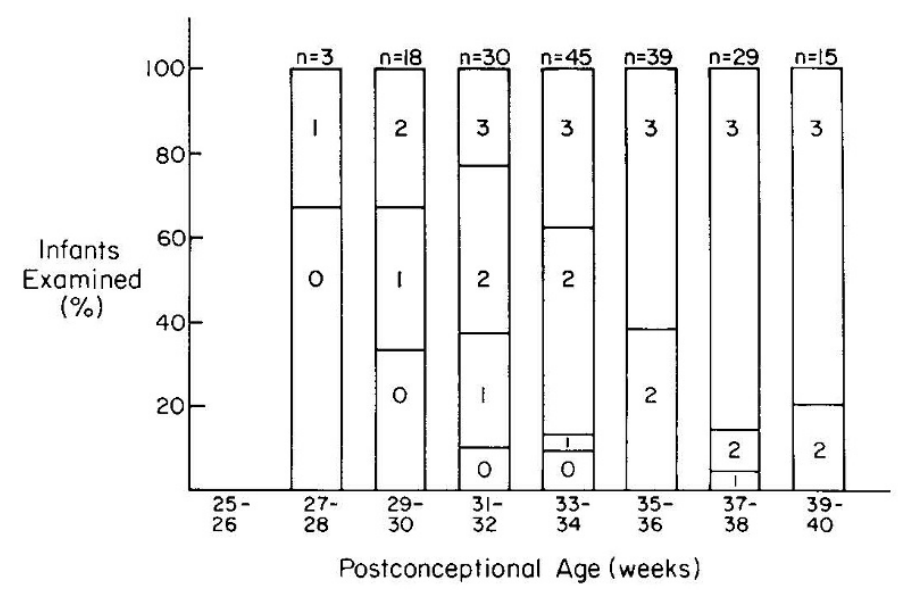

Fig. 6. Lower extremity placing in extremely premature infants prior to term. Grading: $0=$ absent, $1=$ initial flexion only, $2=$ initial flexion, followed by weak and/or delayed extension, 3 = brisk flexion followed by strong, brisk extension.

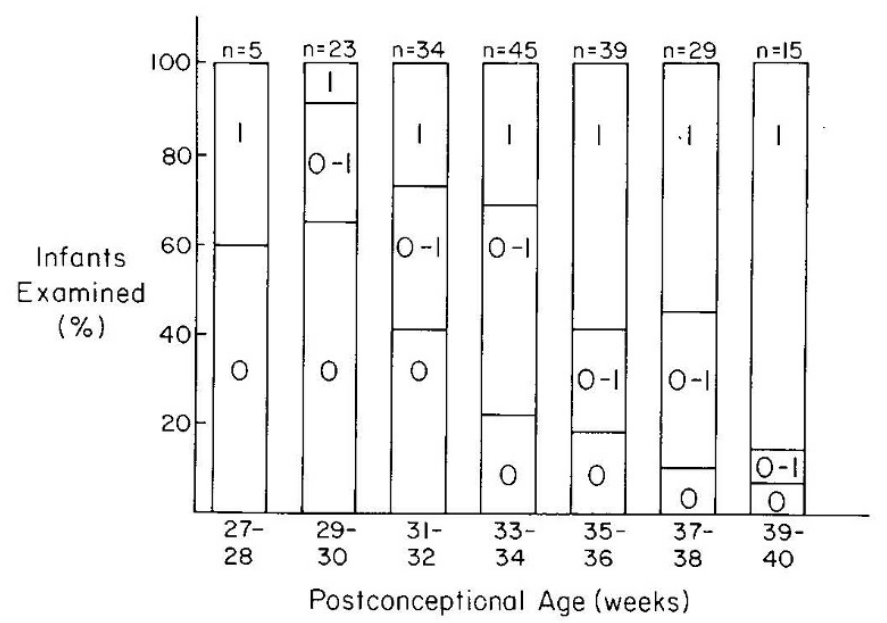

Fig. 7. Positive support in extremely premature infants prior to term. Grading: $0=$ absent, $0-1=$ weight bears inconsistently ( $<3$ of five trials), or for $<1 \mathrm{~s}, \mathrm{l}=$ consistently ( $\geq 3$ of five trials) weight bears for $\geq 1 \mathrm{~s}$. 


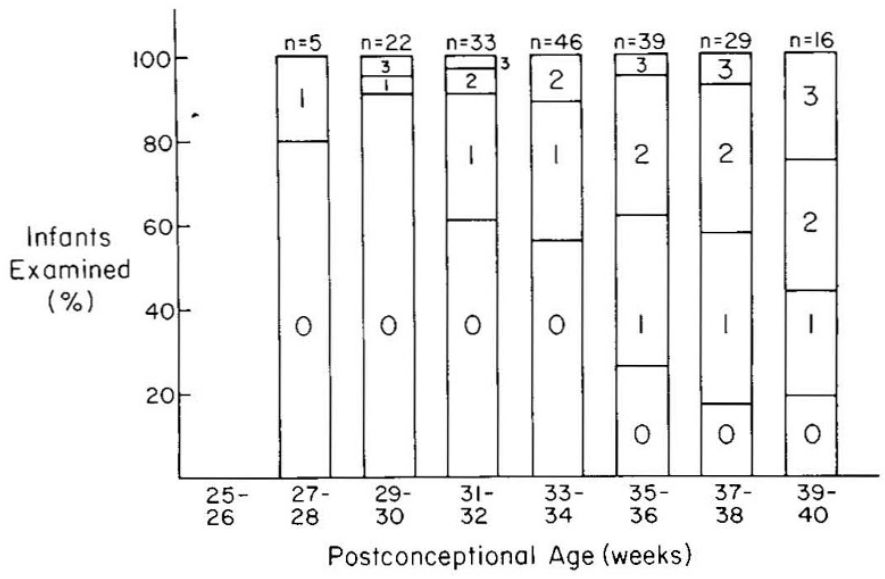

Fig. 8. Stepping reflex in extremely premature infants prior to term. Grading: $0=$ absent, 1 = equivocal and/or inconsistent flexion and extension, 2 = consistent reciprocal flexion and extension, 3 = exaggerated flexion and extension that is easily and consistently elicited.

presence or absence of periventricular/intraventricular hemorrhage. The nine infants with grade I, four with grade II, and one with grade III hemorrhages were analyzed as a group, and compared to the $33(70 \%)$ without hemorrhage. There were no detectable differences in the evolution of any of the primitive reflexes. The infant with grade III intraventricular hemorrhage and the infant with evidence of PVL demonstrated no definite abnormalities in the pattern of developing primitive reflexes.

\section{DISCUSSION}

Careful sequential neurodevelopmental examinations in a population of viable extremely premature infants has allowed this description of the appearance of eight primitive reflexes from $25 \mathrm{wk}$ gestation to term. Three patterns of appearance of the primitive reflexes emerge: 1) the upper and lower extremity grasp reflexes were present in all premature infants, from $25 \mathrm{wk}$ PCA and beyond, 2) the Moro, ATNR, and Galant were present in some premature infants as early as $25 \mathrm{wk}$ PCA, and in the majority ( $\geq 80 \%$ ) by $30 \mathrm{wk}$ PCA, and 3 ) the lower extremity placing, positive support, and stepping were present by $30 \mathrm{wk}$ PCA in a few premature infants, yet were not uniformly present or complete even at term. In each case, the primitive reflex became stronger, more complete, more consistently elicited, and more prevalent with increasing postconceptional age.

The grasp reflex is one of the earliest primitive reflexes that can be elicited. In this study, both upper and lower extremity grasps were present in all viable extremely premature infants $(25$ wk PCA and beyond). Finger flexion in response to stroking the palm has been noted in nonviable aborted fetuses as early as $10^{1 / 2}$ wk gestation, with a more sustained response by $18 \frac{1}{2}$ wk $(24$, $25)$. Stroking the base of the toes of $11 \frac{1 / 2}{2}$ wk nonviable aborted fetuses produced toe flexion, although beyond $12 \frac{1}{2}$ wk this response competed with dorsiflexion of the hallux and toe fanning (23). This competition between the lower extremity grasp reflex and the Babinski response has been described throughout infancy (31). When elicited by pressure at the base of the toes, the lower extremity grasp has been a consistent finding in nonviable aborted fetuses beyond $25 \mathrm{wk}$, viable premature infants beyond $28 \mathrm{wk}$, and full-term neonates $(7,9,32)$.

The upper extremity grasp reflex consists of not only finger flexion, which is present very early, but also flexion at the elbows and shoulders with traction (grades 3 and 4). This emerged at 29 to $30 \mathrm{wk}$ PCA, and, as noted in previous reports, was consistently present by 35 to 36 wk PCA $(9,32,33)$. In comparison with $63 \%$ of full-term newborns (9), $40 \%$ of premature infants at term demonstrated an upper extremity grasp reflex that was strong enough to lift the infant off the bed.

The Moro consists not only of the initial arm extension and abduction generally described $(9,22,32,33)$, but also a subsequent flexion and adduction of the arms $(2,7,10,13)$. The initial extension component of the Moro was present in most viable premature infants, even those 25 wk PCA, and has also been observed in 22 to 25 wk nonviable aborted fetuses $(9,23)$. Some subsequent arm flexion appeared at 27 to $28 \mathrm{wk}$ PCA, and was generally present by 31 to 32 wk PCA. A complete Moro was present in more than half the premature infants by $37 \mathrm{wk}$ PCA, and this is similar to full-term neonates (13).

The majority of these viable premature infants had some evidence of the ATNR in both upper and lower extremities. At 25 to 26 wk PCA, half the infants who had an ATNR demonstrated it only by changes in extremity muscle tone. By 29 to 30 wk PCA, however, the majority of infants demonstrated a change in posture. These findings are consistent with those of Gesell (34) who observed the ATNR (called the "tonic neck reflex") in 28wk gestation premature infants, and believed that there was evidence of an incomplete ATNR in 20-wk nonviable fetuses $(34,35)$. Saint-Anne Dargassies (9), on the other hand, did not observe the ATNR until 35 wk PCA.

Many believe that the ATNR is uncommon in full-term newborns $(4,9,36,37)$. Saint-Anne Dargassies (9) found that the ATNR was strongest at 35 wk PCA in premature infants, weaker thereafter, and uncommon (present in only $21 \%$ ) in full-term newborns. On the other hand, Gesell (34) believed that the tonic neck reflex was universally present in full-term infants from birth to $12 \mathrm{wk}$ of age $(35,38)$. The premature infants at term in this study are similar to the full term newborns studied by Capute et al. (13): most had an ATNR, and half had a pronounced change in posture (grade 3).

This discrepancy as to the presence of the ATNR at term may be related to the criteria used to score the reflex as present. The more hypotonic premature infant at $35 \mathrm{wk}$ PCA has a more dramatic ATNR because of pronounced extension of the extremities on the face side. The increased flexor tone in full-term newborns and in premature infants at term may mask the extensor component of the ATNR. In these infants, the score (as to grade 2 or 3 ) frequently rests with the change in degree of elbow flexion with turning the head. Previous studies, other than those of Capute et al. (13), did not grade the reflex or use this method to score it as present.

Although in this study the Galant was rare at 25 to 26 wk PCA, it appeared rapidly, and was present in most premature infants by 29 to $30 \mathrm{wk}$ PCA. Studies on nonviable aborted fetuses show that the back is sensitive to cutaneous stimulation as early as 14 wk gestation $(23,24)$. Saint-Anne Dargassies (9) noted lateral trunk incurvation in response to paravertebral stimulation in 22-wk nonviable aborted fetuses, in all premature infants at 28 wk gestation and beyond, and in $99 \%$ of full-term newborns (9). Robinson (32) observed the Galant in $87 \%$ of premature infants $28 \mathrm{wk}$ and beyond (32), which is consistent with the findings of this study. The Galant became much stronger with increasing postconceptional age. Half of the premature infants at term had simultaneous elevation of the hips, and this compares favorably with $40 \%$ in full term neonates studied by Capute et al. (13).

The lower extremity placing is described as universally present and complete in full-term newborns $(2,6,9,39)$. Grading this primitive reflex allows elucidation of its pattern of emergence in extremely premature infants. The initial flexion emerged first at 27 to 28 wk PCA, and was followed by delayed or weak subsequent extension at 29 to $30 \mathrm{wk}$ PCA. At term, $80 \%$ of premature infants have brisk flexion followed quickly by brisk extension (a grade 3 response), but $20 \%$ continue to show delayed or weak extension. 
The newborn positive support (grade 1) could be elicited as early as 27 wk PCA, but was not a frequent response until 35 to 36 wk PCA. This coincides with the observation that momentary lower extremity straightening with stimulation of the soles has been noted in 28- to 32-wk gestation premature infants, and spreads to the trunk at 35 to 36 wk gestational age $(9,22)$.

Although more than $80 \%$ of premature infants at term had a grade 1 positive support in this study, less than $20 \%$ of full term newborns studied by Capute et al. (13) had a positive support. Paine (16) notes that full-term newborns commonly assume a semicrouching position while briefly supporting some of their weight. This semicrouched position is not consistent with a grade 1 positive support. As premature infants at term tend to have less flexor tone than full-term newborns (9), they are less likely to assume this position, making the positive support easier to elicit.

The stepping (or automatic walking) reflex has been described as weak but present in some 28 - to 32 -wk premature infants, consistently present at $35 \mathrm{wk}$, and strong and sustained at $37 \mathrm{wk}$ $(9,22)$. Paine et al. (4) found that stepping was variable in fullterm newborns, and that failure to elicit it at a single examination was not proof of its absence. The findings of this study are consistent with these observations. Stepping was rare and inconsistent less than 35 wk PCA, then became progressively more complete, more consistent, and more prevalent from 35 to 40 wk PCA. Fifty-six percent of premature infants at term had stepping, and this compares favorably with $58 \%$ of full-term newborns (9).

Children with grade I and II periventricular/intraventricular hemorrhages do not appear to have a higher incidence of major handicap (40). Therefore it is not surprising that the pattern of primitive reflexes is not different in premature infants with grade I or II hemorrhages. However, because of the small numbers involved in our data analysis, the statistical power of this finding is low, and there is still a definite possibility that a difference in the evolution of primitive reflexes does exist between infants with and without periventricular/intraventricular hemorrhage.

\section{IMPLICATIONS}

Having defined the pattern of appearance of these eight primitive reflexes in a population of viable premature infants, deviation from this pattern can be viewed as suspect. Even at $25 \mathrm{wk}$ gestation, the premature infant should have both upper and lower extremity grasp reflexes. By $30 \mathrm{wk}$, most premature infants have some evidence of the Moro, the ATNR, and the Galant. These three reflexes should be clearly evident by term. On the other hand, the premature infant at term who has an incomplete lower extremity placing reflex, or does not have a stepping reflex or a positive support may still be normal. Examination of the quality of the primitive reflexes may enhance our appreciation of subtle neurologic abnormalities (e.g. asymmetry).

With one exception (positive support), the primitive reflex profile of the premature infant at term compares favorably with that of the full-term newborn reported in the literature $(9,13)$. Mild (grade I or II) periventricular/intraventricular hemorrhages do not appear to affect the primitive reflex profile of premature infants.

Thus premature infants, even as immature as $25 \mathrm{wk}$ gestation, can be assessed neurodevelopmentally. A single examination is not as helpful or as reassuring as sequential examinations. The actual postconceptional age at which a primitive reflex appears is somewhat variable. Sequential examinations allow an appreciation of the total primitive reflex pattern in the extremely premature infant. The predictive ability of these primitive reflexes in premature infants prior to term will be the subject of further investigation.

\section{REFERENCES}

1. St Clair KL 1978 Neonatal assessment procedures: a historical review. Child Dev 49:280-292

2. Paine RS 1960 Neurologic examination of infants and children. Pediatr Clin North Am 7:471-510

3. Peiper A 1963 Cerebral Function in Infancy and Childhood. Consultants Bureau, New York, NY, pp 147-210

4. Paine RS, Brazelton TB, Donovan DE, Drorbaugh JE, Hubbell JP Jr, Sears EM 1964 Evolution of postural reflexes in normal infants and in the presence of chronic brain syndromes. Neurology 14:1036-1048

5. Prechtl HFR, Beintema D 1964 The Neurological Examination of the FullTerm Newborn Infant. Little Club Clinics in Developmental Medicine No. 12, The Spastics Society Medical Education and Information Unit in association with William Heinemann Medical Books Ltd, London, pp 1-74

6. Paine RS, Oppe TE 1966 Neurological Examination of Children, Clinics in Developmental Medicine no. 20/21, The National Spastics Society Medical Education and Information Unit in association with William Heinemann Medical Books Ltd, London

7. Illingworth RS 1972 The Development of the Infant and Young Child, Normal and Abnormal. Williams \& Wilkins, Baltimore, pp 80-109

8. Saint-Anne Dargassies S 1972 Neurodevelopmental symptoms during the first year of life. Dev Med Child Neurol 14:235-246

9. Saint-Anne Dargassies S 1977 Neurological Development of the Full-Term and Premature Neonate. Excerpta Medica, New York, NY, pp 13-36, 179224

10. Capute AJ, Accardo PJ, Vining EPG, et al 1978 Primitive Reflex Profile. University Park Press, Baltimore, pp 1-91

11. Capute AJ, Wachtel RC, Palmer FB, Shapiro BK, Accardo PJ 1982 A prospective study of three postural reactions. Dev Med Child Neurol 24:314320

12. Capute AJ, Shapiro BK, Accardo PJ, Wachtel RC, Ross A, Palmer FB 1982 Motor functions: associated primitive reflex profiles. Dev Med Child Neurol 24:662-669

13. Capute AJ, Palmer FB, Shapiro BK, Wachtel RC, Ross A, Accardo PJ 1984 Primitive reflex profile: A quantitation of primitive reflexes in infancy. Dev Med Child Neurol 26:375-383

14. Palmer FB. Shapiro BK, Wachtel RC, Capute AJ 1983 Primitive reflex profile. In: Thompson GH, Rubin IL, Bilenker RM (eds) Comprehensive Management of Cerebral Palsy. Grune and Stratton, New York, NY, pp 171-179

15. Touwen BCL 1984 Primitive reflexes-conceptional or semantic problem? In: Prechtl HFR (ed) Continuity of Neural Functions from Prenatal to Postnatal Life. Spastics International Medical Publications, JB Lippincott Co, Philadelphia, pp 115-125

16. Paine RS 1964 The evolution of infantile postural reflexes in the presence of chronic brain syndromes. Dev Med Child Neurol 6:345-361

17. Milani-Comparetti A, Gidoni EA 1967 Pattern analysis of motor development and its disorders. Dev Med Child Neurol 9:625-630

18. Stern RM 1971 The reflex development of the infant. Am J Occup Ther 25:155-158

19. Molnar GE, Gordon SU 1976 Cerebral palsy: predictive value of selected clinical signs for early prognostication of motor function. Phys Med Rehab 57:153-158

20. Capute AJ, Accardo PJ, Vining EPG, Rubenstein JE, Waicher JR, Harryman S, Ross A 1978 Primitive reflex profile. A pilot study. Phys Ther 58:10611065

21. Capute AJ 1979 Identifying cerebral palsy in infancy through study of primitive reflex profiles. Pediatr Ann 8:10-15

22. Amiel-Tison C 1968 Neurological evaluation of the maturity of newborn infants. Arch Dis Child 43:89-93

23. Hooker D 1969 The Prenatal Origin of Behavior. Hafner Publishing Co, New York, NY, pp 54-86

24. Humphrey $T 1964$ Some correlations between the appearance of human fetal reflexes and the development of the nervous system. Prog Brain Res 4:93135

25. Humphrey T 1969 Postnatal repetition of human prenatal activity sequences with some suggestions of their neuroanatomical basis. In: Robinson RJ (ed) Brain and Early Behavior, Development in the Fetus and Infant. Academic Press, New York, NY, pp 43-84

26. Birnholz JC, Stephens JC, Faira M 1978 Fetal movement patterns: a possible means of defining neurologic developmental milestones in utero. AJR 130:537-540

27. Britton SB, Fitzhardinge PM, Ashby S 1981 Is intensive care justified for infants weighing less than $801 \mathrm{gm}$ at birth? J Pediatr 99:937-943

28. Bennett FC, Robinson NM, Sells CJ 1983 Growth and development of infants weighing less than 800 grams at birth. Pediatrics 71:319-323

29. Hirata T, Epcar JT, Walsh A, Medrick J, Harris M, McGinnis MS, Sehring S, Papedo G 1983 Survival and outcome of infants 501 to $750 \mathrm{gm}$ : a six-year experience. J Pediatr 102:741-748

30. Dubowitz LMS, Dubowitz V, Goldberg C 1970 Clinical assessment of gestational age in the newborn infant. J Pediatr 77:1-10

31. Feldman WM 1922 The nature of the plantar reflex in early life and the causes of its variations. Am J Dis Child 23:1-40

32. Robinson RJ 1966 Assessment of gestational age by neurological examination. Arch Dis Child 41:437-447

33. Coutts NA 1971 Neurological assessment of gestational age in low birth weight 
infants. Scott Med J 16:398-403

34. Gesell A 1945 The Embryology of Behavior, Harper and Brothers, New York, NY, pp 61-75, 107-122

35. Gesell A 1954 Behavior patterns of fetal-infant and child, with evidence of innate growth factors, In Hooker D, Hare C (eds) Genetics and Inheritance of Neuropsychiatric Patterns. Res Publ Assoc Res Nerv Ment Dis 33:114126

36. Thomas A, Chesni Y, Saint-Anne Dargassies S 1960 The Neurological Examination of the Infant. Little Club Clinics in Developmental Medicine no. 1, National Spastics Society, London, pp 1-31
37. Vasella F Karlsson B 1962 Asymmetric tonic neck reflex. A review of the literature and study of its presence in the neonatal period. Dev Med Child Neurol 4:363-369

38. Gesell A 1938 The tonic neck reflex in the human infant. J Pediatr 13:455464

39. Zapella M 1963 The placing reaction in the newborn. Dev Med Child Neurol 5:497-503

40. Papile LA, Munsick-Bruno G, Schaefer A 1983 Relationship of cerebral intraventricular hemorrhage and early childhood neurologic handicaps. J Pediatr 103:273-277

\section{Announcements}

\section{Meeting}

The 27th meeting of the Teratology Society will be held from June 14-18, 1987 at the Marriott Rancho Las Palmas Resort, Palm Springs, CA (92270). The Behavioral Teratology Society will meet in conjunction with The Teratology Society.

Abstracts must be postmarked no later than January 15, 1987. For further information please contact the Administrative Assistant of the Society: Ms. Alexandra Ventura, Administrative Assistant, Teratololgy Society, 9650 Rockville Pike, Bethesda, MD 20814.

\section{The 1987 Written Examination of the American Board of Pediatrics}

The 1987 Written Examination of the American Board of Pediatrics will be administered on Friday, September 11 in various cities throughout the United States, Canada, and Puerto Rico.

Application material for the certifying examinations of the Board is available throughout the year by writing to the Board Office at the address below. The completed material of those applicants who wish to be considered for the 1987 Written Examination must be postmarked by January $31,1987$.

A physician whose application or re-examination registration material is postmarked after the published deadline (January 31 for new applications and February 28 for reexamination registration material) will be assessed an additional fee of $\$ 200$ before the application or registration material will be processed. New applications and reexamination registration material will not be accepted after May 31 of the year of the examination. American Board of Pediatrics, 111 Silver Cedar Court, Chapel Hill, NC 27514 919/ 929-0461. 